\title{
Unintended Consequences: Ambiguity Neglect and Policy Ineffectiveness
}

\author{
Lorán Chollete ${ }^{1}$. Sharon G. Harrison ${ }^{2}$
}

Published online: 1 February 2021

(c) EEA 2021

\begin{abstract}
When a policymaker introduces a novel policy, she will not know what citizens' choices will be under the policy, and citizens themselves may have to construct new choice sets. This imparts inherent ambiguity to novel policy implementation: The policymaker does not know the probability that citizens will select actions that align with her policy. Assuming that citizens will follow a fixed approach may expose the policymaker to ambiguity neglect, which can result in unintended consequences. We provide examples and a simple formalization. Our results suggest that before implementing novel policies, policymakers should attempt to elicit preferences from citizens.
\end{abstract}

Keywords Ambiguity neglect · Choice construction · Externalities · Policy ineffectiveness · Unintended consequences

JEL Classification D78 $\cdot$ D8 $\cdot$ E61

\section{Introduction}

And it came to pass...that he said, Escape for thy life; look not behind thee... lest thou be consumed... But his wife looked back from behind him, and she became a pillar of salt. Genesis 19: 17-26.

Individuals do not always follow orders, even when the consequences may be highly detrimental to them. We may fail to adhere to the choices that a policy intended to elicit because of resource constraints, stubbornness, behavioral considerations, bounded rationality, and other factors that lead us to depart from obedience. If

Sharon G. Harrison

sh411@columbia.edu

1 Welch College of Business and Technology, Fairfield, CT, USA

2 Department of Economics, Barnard College, 3009 Broadway, New York, NY 10027, USA

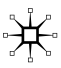


enough citizens disobey a policy mandate, the policy may end up bringing about unintended consequences. Our concept of unintended consequences denotes policy outcomes that differ from the goals of the policymaker. This definition builds on that of Merton (1936), who used the term 'unanticipated consequences' in sociology. ${ }^{1}$

When a government enacts a novel policy that affects us, we may not even know in advance how we shall respond. Hence, in novel situations, some individuals have to construct their choices. Sometimes the new choice involves a simple re-optimization in light of an added budget constraint. At other times, the novel policy may end up creating a new market (Siebert 2003), or distort resource allocation when attempting to introduce a beneficial social norm (Antecol et al. 2018). It is well known from consumer theory that adding an extra constraint can modify choices in nontrivial ways, in particular if the good is a necessity or Giffen good, if there is failure of preference convexity, or if the previous optimum was at a corner solution (see chapters 2 and 3 of Mas-Colell et al. 1995). There is also a substantial psychology literature on preference construction. ${ }^{2}$ This latter research emphasizes that in actual decision-making contexts, individuals often need to construct their preferences.

The above considerations suggest an inherent ambiguity in the case of novel policies: Policymakers do not know the probability that individuals' choices will respond to the policy in a particular manner, because the individuals themselves do not know. At times, policymakers nevertheless implement such novel policies, without accounting for the potential uncertainty in the probability of citizen compliance. For example, in this paper we will use the policy discussed in Davis (2008). In Mexico City, a desire to combat pollution led to a policy that mandated limits on days that each car could be driven. This resulted in citizens' purchasing additional cars, which yielded an increase in pollution.

Sometimes a policymaker has to solve a society-wide issue by either implementing a policy or else do nothing. If she implements the policy, she has to decide what she believes about citizens' preferences or choices. In particular, she may assume that citizens' spending patterns will roughly stay the same, and they will continue economic activity that is similar to what they did before. What she does not account for is that, in response to her policy, some citizens may materially change their choices and behavior. Evidently, this new behavior could encompass non-compliance with the law. However, even if citizens comply with the letter of the law, they may find legal ways to circumvent the spirit of the law (such as purchasing an extra car when there are limits placed on how much each car can be driven).

We refer to policymakers' disregard of uncertainty as ambiguity neglect. While aversion to ambiguity has been studied in a variety of related contexts (Dequech 2000), the topic of willful neglect of ambiguity has received rather less attention. The focus of our paper is on unintended consequences, as outlined above, and developed in our motivating examples of "Our Motivating Examples" section. Ambiguity

\footnotetext{
${ }^{1}$ Examples of recent policies with unintended consequences may be found at http://sharongharrison .blogspot.com/. We provide specific motivating examples in "Our Motivating Examples" section.

2 See Lichtenstein and Slovic (2006) for a comprehensive overview, as well as related research by Kahneman et al. (1999), Payne et al. (1999), and Simon et al. (2008).
} 
plays a role in the following manner. In particular, ambiguity manifests itself when policymakers implement policy solutions for extant challenges (such as pollution), under the assumption that all citizens will follow the policies. In this regard, our model is related to the recent literature on unforeseen contingencies, as studied by Ghirardato (2001), Epstein et al. (2007), and Kochov (2018), among others.

Our work is also related to previous decision theoretic literature on ambiguity (Gilboa and Schmeidler 1989; Schmeidler 1989). This literature sees ambiguity as a central concern. Building on such literature, we are motivated by policy situations such as the above. In such policy situations, the policy decisionmaker did not attend to ambiguity that arose from other actors (e.g., 'disobedient' citizens). The policymaker may neglect ambiguity for a number of reasons, such as career concerns (Brunnermeier et al. 2013), limited Bayesianism (Minardi and Savochkin 2019), and behavioral factors (Benartzi and Thaler 1995; Kahneman 2011). We further discuss the role of ambiguity neglect in "Discussion" section.

Given our policy focus in the present paper, we incorporate a reduced form for capturing the role of ambiguity. Our model summarizes the above considerations by saying that the policymaker does not account for a particular type of ambiguity; namely, that the probability $p$ of disobedience is unknown and potentially nonzero. ${ }^{3}$

What should a policymaker learn from our model? The present paper indicates a basic mechanism through which policies can become ineffective and thereby generate unintended consequences. The mechanism is that by assuming that citizens will obey the policy, it runs the risk of backfiring. The reason is that some citizens may disobey the policy and therefore make the policy ineffective. The main lesson for policymakers is that before implementing novel policies, they should attempt to uncover potential sources of ambiguity. In particular, as discussed in Conclusion, policymakers can attempt to glean a sense of citizens' responses to the policy beforehand, by conducting questionnaires about their expected behavior. Once the potential for ambiguity is perceived, then the policymaker will be able to express attitudes towards ambiguity, be they ambiguity averse, ambiguity neutral, or ambiguity seeking.

Our goal in this paper is to present a simple model of unintended consequences in policy, which may serve as a starting point for future explorations of unintended consequences. One implication of this model is that before implementing new policies, governments and policymakers should attempt to elicit preferences from the citizens who will be affected. The model also lends itself well to being evaluated in empirical and experimental settings. ${ }^{4}$ The rest of this paper proceeds as follows. In the next section, we discuss some examples of unintended consequences, along with some frameworks within which we place these examples. In "A Building Block for

\footnotetext{
${ }^{3}$ In separate work in progress, the authors are developing a broader model that can account for ambiguity attitudes of the policymaker, if she suspects that hidden ambiguity and unintended consequences exist in her decision environment.

4 An immediate experimental implementation is to assess the proportion of the population that will follow the letter and spirit of a novel policy. In work in progress, with Pietro Battiston, we plan to carry out experiments to achieve this in the context of forced contributions to a public good. Our approach builds on the frameworks of Ledyard (1995), Cherry et al. (2013), and Cartwright and Stepanova (2017).
} 
the Model" and "Our Model of Unintended Consequences" sections, we present our model and discuss its implications. In "Conclusion" section, we conclude.

\section{Frameworks to Conceptualize Unintended Consequences}

Unintended consequences develop in numerous socioeconomic settings. They result because human behavior is complex and often unpredictable. In our leading examples below, a new policy is enacted by officials with a particular goal in mind. That goal might or might not be achieved, because citizens react with unintended, often unexpected, behavior. How can policymakers improve their practices, so as to avoid negative unintended consequences, when possible? ${ }^{5}$ An important first step in addressing this question is to model situations where unintended consequences are inherent. In the present paper, we make progress in this regard. In Table 1, we categorize different frameworks from which to view unintended consequences.

Once one reads the vast literature on unintended consequences, it becomes clear that there are multiple perspectives from which to view it. Hence, we do not claim that Table 1 contains an exhaustive list-it does at least attempt to categorize the different frameworks that might be effective in modeling unintended consequences. For economists, a natural question may be, why are unintended consequences different from concepts such as externalities and moral hazard? This table makes clear that externalities and moral hazard represent subsets of unintended consequences.

We categorize the frameworks as either public or private and either market based or nonmarket based. Our model will be one of Externalities, which we categorize as public and market based. Hence, we defer discussion of this framework until later. Another public framework that is nonmarket based is Perverse Incentives such as the cobra effect (Siebert 2003). Here, the proposed solution to a problem winds up worsening the problem. Its origin is in British colonial India: In an attempt to reduce Delhi's cobra population, local policymakers issued a reward for dead cobras. Subsequently, the local citizens started breeding cobras in order to obtain rewards. Once policymakers realized the situation, they removed the reward. At this juncture, the citizens released their newly bred cobras, which had now become valueless. Ultimately, Delhi's cobra population increased, in the aftermath of the aforementioned reward policy. We depict this sequence of events in Fig. 1. In the cobra effect, the unintended consequence involves increasing resources, and thereby unintentionally creating a novel market.

Similarly, Braess' paradox (Braess 1969) states that adding roads to a congested area of traffic can end up increasing traffic congestion. Another example of nonmarket based, public unintended consequences is Campbell's law (1979), which states that excessive use of quantitative social indicators for policymakers tends to make them susceptible to corruption and therefore worthless. Goodhart's law (Goodhart

\footnotetext{
5 Although our model focuses on negative unintended consequences, society may also experience positive unintended consequences. A positive example is the 'invisible hand' of capitalist activity (Smith 1776), where self-interested behavior can end up being optimal for society.
} 


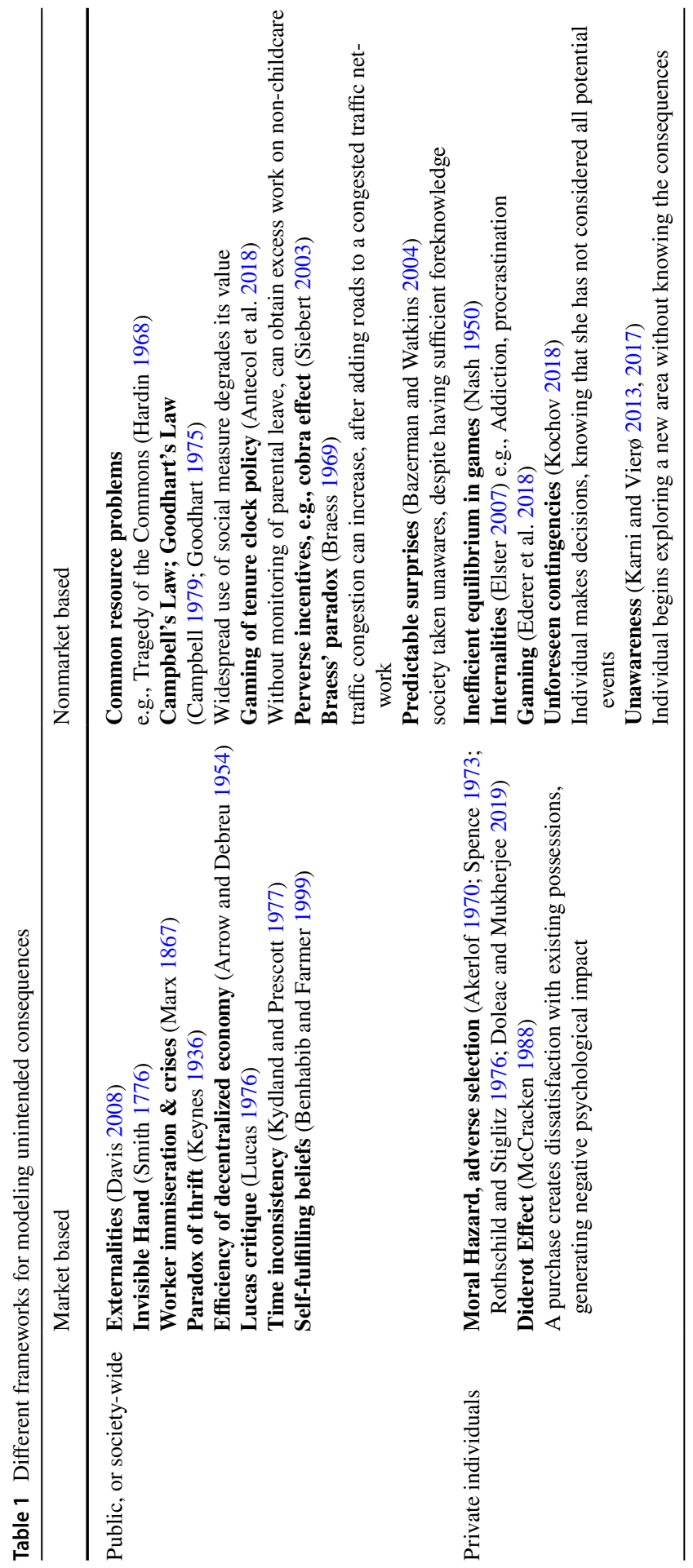

尔 


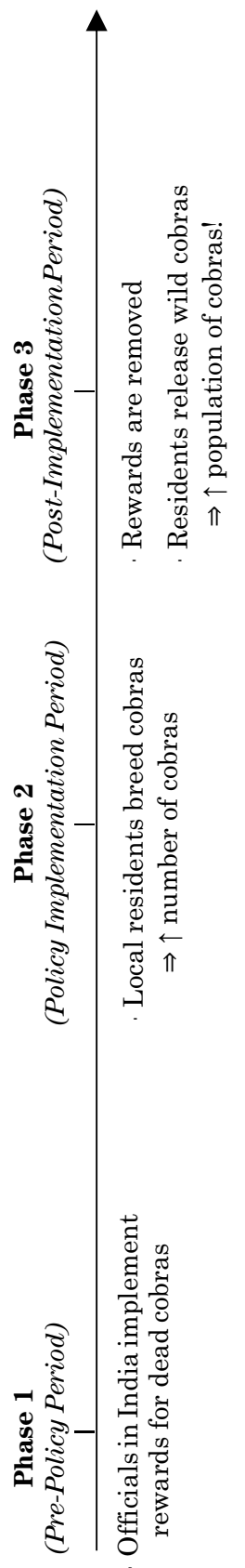


1975) states that when a statistical measure is targeted, it ceases to become effective, and the McNamara fallacy indicates that focusing on quantitative measures and assuming that nonmeasurable data are irrelevant can end up damaging policy decisions. In their work on predictable surprises, Bazerman and Watkins (2004) outline scenarios where socially negative events such as corruption and climate change take policymakers by surprise, despite their possessing the advance knowledge to anticipate such events.

Continuing with nonmarket-based examples, those that affect private individuals include Nash (1950), who demonstrated that while it is individually rational for agents in a strategic game to choose noncooperation, if all agents do this, it makes everyone worse off. ${ }^{6}$ Also in this category is research on gaming, where a policymaker assigns tasks to agents with hidden information, who have an incentive to focus on less costly tasks (Ederer et al. 2018). Another prominent class of unintended consequences in this area includes unforeseen contingencies (Kochov 2018). In these situations, the decisionmaker cannot completely foresee all outcomes and is aware of her lack of ability to foresee. A related class of unintended consequences in this category comprises situations of individual unawareness (Karni and Vierø 2013 , 2017), such as when a scientist or explorer embarks on a new venture. In situations of unawareness, many consequences are unintended, because the individuals themselves do not know what will transpire. Lastly, we include the concept of Internalities, which is prominent in sociology and other disciplines. An internality is a spillover effect that individuals impose on themselves. For example, procrastination today will negatively affect one's choice set in the future. See Elster (2007).

Many of the above examples come from various disciplines in the social sciences. As economists, we are particularly interested in the examples of market-based unintended consequences working from the perspective of society, which have long played a role in economic thought. We discuss four. First, Mandeville (1714) and Smith (1776) explored the public benefits of privately selfish behavior, in defense of an emerging capitalism. Subsequently, the notion that self-interested individuals could inadvertently work for the good of society was formally established by Arrow and Debreu (1954), among others. Second, Marx (1867) developed a theory of economic crises, based on each capitalist saving by laying off workers, which ends up reducing demand for the capitalist firm's output, which in turn diminishes profits even further. Third, in a similar vein, Keynes (1936) discusses the 'paradox of thrift,' where citizens increase their savings at the onset of a downturn, which reduces aggregate demand, thereby worsening the downturn. Fourth, Lucas (1976) critiqued the application of economic policy based on historical relations such as the Phillips curve, because once citizens realize policymakers' intent, the citizens will adjust their expectations and nullify the policy effect.

\footnotetext{
${ }^{6}$ In our taxonomy, we use the term nonmarket based to denote activities that may or may not occur in a market setting. Thus, for example, in Table 1 we classify inefficient equilibrium in games as nonmarket based because these phenomena, such as the battle of the sexes, can occur in nonmarket settings (Fudenberg and Tirole 1991, Chapter 1, section 2.4).
} 
Other examples from economics include those that are market based from the private perspective. Akerlof (1970), Spence (1973), and Rothschild and Stiglitz (1976) demonstrate that in the presence of asymmetric information, individually rational behavior can lead to market failures. In addition, many classic examples of unintended consequences problems can be framed as situations of moral hazard or adverse selection. For a contemporary example of moral hazard, see Doleac and Mukherjee (2019).

\section{Our Motivating Examples}

We now discuss two salient examples of unintended consequences in economics. These two examples, studied by Antecol et al. (2018), and Davis (2008), respectively, form an important part of our modeling exercise in "A Building Block for the Model" section.

Example 1 (Tenure Clock Stopping Policies in Academia) Antecol et al. (2018) study the introduction of gender-neutral clock-stopping policies meant to 'level the playing field' in terms of tenure achievement between male and female assistant professors. Initially, colleges and universities created such policies only for women. However, it is now most common for these policies to be gender-neutral. Antecol et al. (2018) investigate these policies at the top 50 institutions in economics and find that males at an institution with a gender-neutral clock stopping policy have about a $17 \%$ higher probability of getting tenure at their first job, whereas women are about $19 \%$ less likely. What seems to be happening is that at the most prestigious institutions, the clock stopping policy allows men time to produce additional publications at top 5 journals in Economics. ${ }^{7}$

The above example has features of gaming, and creation of a new market as in the cobra effect. However, we can also express this example in terms of externalities. In this case, there are positive externalities to having a parent at home: The interactions of the parent with the spouse at home, and the children who are cared for, improved resource allocation and fairness to mothers who spend more time in child rearing relative to their male counterparts. The goal of the policy is to increase these externalities. However, as the above demonstrates, some individuals find a way to circumvent the policy, in this case reducing the positive externalities.

Example 2 (Air Pollution Reduction in Mexico City) In 1989, the government of Mexico City tried to control air pollution by banning most drivers from driving their vehicle one weekday per week. This policy is still in place today. Violators of this policy were charged a large fine. The policy backfired: Many drivers bought another car-often a used, high emissions car, which ended up worsening the pollution

\footnotetext{
7 It should be noted that the authors find no effect on overall tenure rates for these women in the profession as a whole.
} 
(Davis 2008). In this case, every driver's decision to drive creates the negative externality of air pollution. The unintended consequence of drivers buying an additional used car made this negative externality even worse.

\section{A Building Block for the Model}

In this section, we develop a basic framework for unintended consequences, which clarifies what we believe to be salient issues, including ambiguity neglect. For the sake of simplicity, we focus on a canonical case of aggregate externalities. We evidently downplay other potentially salient aspects of unintended consequences, such as those in Table 1. It is also worth noting that, while outside of the scope of the present paper, we feel that useful extensions of our analysis may readily incorporate other factors.

Before laying out the formal model, we place the above examples and discussion in context and imagine a more general setting, as follows. A basic approach is to consider an individual decisionmaker who chooses actions $a_{i}, i=1, \ldots, I$ from a finite set $A$ of all actions. Each action has a consequence $c_{j}, j=1, \ldots, J$ which is in a corresponding finite set $C$. To fix ideas, suppose there is only one action $a_{1}$ and there are only two outcomes $(I=1 ; J=2)$.

$$
\text { Action } a_{1} \Rightarrow \begin{aligned}
& \text { Intended Consequence }(\mathrm{s}) c_{1} \text {, with probability } 1-p \\
& \text { Unintended Consequence }(\mathrm{s}) c_{2} \text {, with probability } p
\end{aligned}
$$

While we focus in the present paper on neglect of the probabilities, an alternative approach is to consider that the consequences $c_{2}$ themselves (not just their probabilities) are unknown. ${ }^{8}$ Such situations have recently been studied in decision theory, by Karni and Vierø $(2013,2017)$.

\section{Illustrative Examples}

To illustrate this simple model, we provide three further examples from the real world, of a policymaker taking one action with two potential consequences, one intended and one unintended.

Example A1 (Social Distancing due to novel coronavirus) Here, $a_{1}$ is a political leader's decision to mandate social distancing among citizens. $c_{1}$ is the intended outcome of the policy, say, a reduction in cases of novel coronavirus. $c_{2}$ is an unintended outcome, namely an inadvertent drop in GDP, because many citizens cannot attend work or are laid off.

\footnotetext{
${ }^{8}$ In situations of 'unawareness', it is not just $p(C)$ that is unknown, but the state space $C$ itself expands. The discovery of new outcomes corresponds to scientific discoveries, geographical exploration, learning about outcomes in the political economy of voting, and so on.
} 
Example A2 Tariffs. Here, $a_{1}$ is a particular choice of increasing tariffs by a country's leaders, with $c_{1}$ being a hoped-for improvement in the current account. $c_{2}$ is a worsening of the current account, because citizens purchase less from overseas, which causes the currency to appreciate and therefore ends up reducing overseas demand for the country's products.

Example A3 (Central Bank Interest Rate Policy) Here, $a_{1}$ is a central bank's decision to cut interest rates. $c_{1}$ is the intended outcome of the central bank, say, an increase in investment and spending. $c_{2}$ is an unintended outcome such as inflation, or an inadvertent drop in borrower quality, which may precipitate financial instability.

\section{Building Further on the Model}

In particular, what we have in mind is a policymaker who, at the beginning of time, $t=0$, faces an undesirable social or economic situation can either do nothing or decide to enact a new policy $x \in X$ or, where $X$ is the set of all possible actions the policymaker may take. At the same time, the policymaker knows that the policy will affect a finite number $N$ of citizens, who are indexed $i=1, \ldots, N$. The policymaker assumes that all (or the majority of) citizens have preferences $u_{i}=\bar{u} \in U$, where $U$ is a finite set of all available preferences. For instance, in Example 2, the policymaker may believe that $\bar{u}$ represents preferences that are decreasing in the large percar fine of $f$, which would therefore reduce demand for car use. However, in actuality, the dominant effect was a different set of preferences, say, $u_{c}$, where $u_{c} \neq \bar{u}$, which some proportion, $p$, of the population constructed after the policy.

A graphical depiction of the timeline is in Fig. 2.

- 1. First (beginning of $t=0$ ), the policymaker assesses what she thinks citizens' preferences $\bar{u}$ are and, in light of that assessment, decides whether or not to enact a novel policy.

- 2. Second (end of $t=0$ ), she enacts the policy and citizens then decide to construct their preferences $u_{c}$, which may or may not coincide with $\bar{u}$.

- 3. Third $(t=1)$, the policy effect is observed. If the policy effect is different from what the policymaker intended, we describe the model as delivering unintended consequences.

\section{Discussion}

With the above approach summarized in Eq. (1) and Fig. 2, we can start building a simple taxonomy for unintended consequences. To begin with, we assume that $p$ is an exogenously given number between 0 and 1 . Though the policymaker knows it exists, she acts as if $p=0$ and ignores the possibility of the unintended consequence, $c_{2}$, occurring. That is, she is subject to ambiguity neglect.

There is a large decision theoretic literature on ambiguity, where a decisionmaker faces an unknown distribution of outcomes. In this literature (Gilboa and Schmeidler 1989; Schmeidler 1989), the decisionmaker sees ambiguity as a central concern 


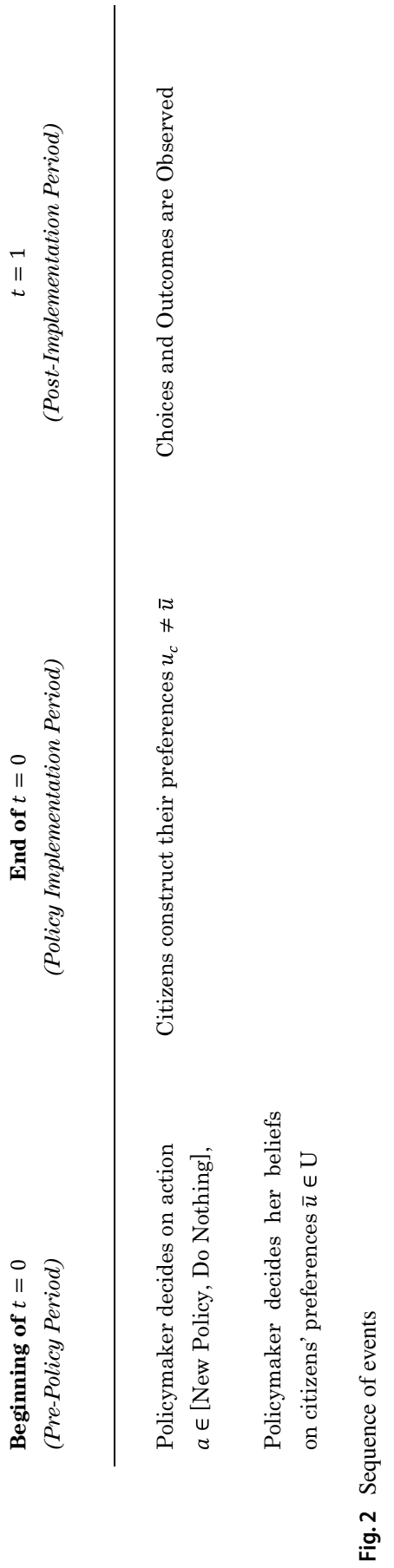

25 
in their decision making. In our paper, it is similarly important to understand the impact of ambiguity. However, as mentioned above, we are motivated by policy situations that failed, because the initial decisionmaker did not attend to ambiguity that arose from other actors (e.g., 'disobedient' citizens).

Why might a policy decisionmaker neglect ambiguity? There are a number of potential answers to this question. Merton (1936) himself gives several reasons. These include that, given the lack of knowledge of all the possible outcomes, it is just not worth the effort to try to predict all of them. A second, related, reason he gives is 'imperious immediacy of interest.' By this, he means that a policymaker is so set on the intended outcome of a policy that she willfully ignores the other possible outcomes. Hence, this reason is different from pure ignorance.

On a practical level, one possibility is that political pressure to be seen as proactive can force the policymaker to act, rather than be seen as doing nothing. Second, if the policymaker expresses uncertainty about the policy outcome (i.e., acknowledges that there is ambiguity), then she may be perceived as weak, indecisive, and ineffectual (Brunnermeier et al. 2013). Such a perception can be costly for a policymaker with career concerns. There is some precedent in economic literature for considering decisionmakers who disregard important information. For example, Ortoleva and Snowberg (2015) analyze the implications of over-confident individuals, who neglect correlations. A similar approach to correlation neglect is considered by Levy and Razin (2015) in a political economy setting. One possible way to conceptualize such neglect of information is to allow for the decisionmaker to be Bayesian, but only on the set of states that she takes into account (Minardi and Savochkin 2019). Beyond such economic research, there exists a large psychological literature on behavioral biases. This latter literature emphasizes that individuals may be short-sighted or process information incorrectly when making decisions, as in the work of Benartzi and Thaler (1995), and Kahneman (2011), among others.

Other explanations include cognitive limitations or bounded rationality. For instance, the policymaker might face a difficulty in processing low-probability events (Hertwig et al. 2005), or be driven by emotional reactions (Lerner and Keltner 2001; Elster 2007). They may also exhibit limits to attention (Sims 2003). In addition, the reason might arise because of tribalism and myths. Economic policymakers may enact policy under the assumption that citizens respond to truth or data that the citizens are credibly told. However, anthropological research indicates that humans often respond more to the myth or story about the particular policy, rather than to some quantifiable numerical 'fact.' In such situations, unintended consequences follow from policymakers' assumption that individuals respond to certain information, whereas in reality individuals respond to different information. This builds on behavioral literature: Not only are there biases in processing data, but sometimes individuals may not even look at the data in making their decisions (Shiller 2017).

In addition, a compelling reason for responding to non-verifiable information is biological in nature. Indeed, some scientists aver that such behavior may confer an evolutionary advantage when practiced at a society-wide level (Dennett 2007). As noted above, in a separate scientific area, anthropologists suggest that throughout history, humans have survived on the basis of their ability to believe collectively in abstractions such as gods, value of currency, and laws (Harari 2015). The vestiges of 
such tribal behavior may mean that humans at times value narrative more than fact. Viewed from this perspective, consequences that are unintended from the viewpoint of a politician or economist who focuses on non-tribal facts (such as which policy is financially better for a group of voters), will not be surprising to a social scientist who places some weight on voters' tribal considerations. ${ }^{9}$

Why might citizens not just follow the rules? There are several reasons why citizens' constructed choices may not agree with what policymakers predicted: First, some people may just be contrarian and do not like to be told what to do-they experience a psychic cost to obediently following the rule (regardless of whether a financial cost is involved). Second, some individuals are corrupt and do not wish to follow regulations that force them to make payments. Third, some individuals are motivated by behavioral factors, and either do not fully understand the policy intent or genuinely do not know what their optimal choices are. ${ }^{10}$

Hence, we suggest that choice construction (of individuals) and ambiguity neglect (by policymakers) may be a driving force behind certain policy failures. It is not necessary that all citizens choose differently from what was predicted by the policymaker: In Example 1 of tenure clock stoppages, only a fraction $p$ of the population did not behave as the policymakers expected.

\section{Our Model of Unintended Consequences}

In this section, we formalize our model. A policymaker introduces a new policy. At the time of implementation, the policymaker knows the citizens' choices, but does not know what the choices will be under the policy. In particular, upon implementation, some proportion $p$ of the citizens will not act in accord with the policy, and the rest will obey. The policymaker does not know this proportion and does not know how preferences will change (for instance, in Example 2, that the citizens will buy another car). Moreover, the policymaker assumes her policy will work in terms of increasing total welfare and acts as if the proportion $p$ equals zero or is negligible. By ignoring the probability $p$, the policymaker is subject to ambiguity neglect. In fact, the citizens themselves may not know what their preferences and choices will be under the new policy and will have to construct them in real time. ${ }^{11}$ Table 2 outlines and interprets key variables in our analysis.

The formulation below sketches the main ingredients in our approach to unintended consequences. It summarizes key features of extant findings such as those presented in our Example 1 (due to Antecol et al. 2018) and Example 2 (due to

\footnotetext{
${ }^{9}$ For much of human history, numerical 'facts' pertaining to socioeconomic issues have not been considered to be as important as beliefs about the particular situations, see Poovey (1998).

${ }^{10}$ For literature on the role of disobedience in society, see Davide and Passini (2010), Bocchiaro et al. (2012), Bocchiaro and Zimbardo (2017), and http://intelligentdisobedience.com/books/. For research on corruption, see Andvig and Moene (1990). For emotional and behavioral factors, see Lerner and Keltner (2001), and Rashes (2001).

11 For background on preference construction, see Kahneman et al. (1999) and Lichtenstein and Slovic (2006).
} 
Table 2: Notation and terminology

\begin{tabular}{|c|c|c|}
\hline Term & Description & Further interpretation \\
\hline $\bar{X}$ & Aggregate externality, before policy & $\bar{X} \in(0,1)$, scales utility down. \\
\hline$X$ & $\begin{array}{l}\text { Aggregate externality after policy, assuming ever citizen } \\
\text { obeys }\end{array}$ & $X>1$, scales utility up. \\
\hline$X^{\text {net }}$ & Net externalities when some citizens disobey & $X^{\text {net }}<X$ \\
\hline $\bar{u}$ & Utility levels for citizens, before policy & $\bar{u}>0$ \\
\hline$u$ & Utility levels for obedient citizens, after policy & $u>0 ; u<\bar{u}$ \\
\hline$u^{c}$ & $\begin{array}{l}\text { Utility levels for disobedient citizens, after policy c denotes } \\
\text { 'constructed' }\end{array}$ & $u^{c}>\bar{u}$ \\
\hline $\bar{U}$ & Total welfare before policy enactment & \\
\hline$U$ & Total welfare after policy, when all citizens obey & \\
\hline$U^{C}$ & Total welfare after policy, when some citizens disobey & \\
\hline$p$ & Proportion of citizens who disobey & \\
\hline $\bar{p}$ & Threshold probability such that $U=U^{C}$ & \\
\hline \multirow[t]{2}{*}{$E=\frac{U-U^{C}}{N}$} & $\begin{array}{l}\text { Per capita increase in welfare after policy, when some } \\
\text { citizens disobey }\end{array}$ & Policy is effective if $E>0$ \\
\hline & & Policy is ineffective if $E \leq 0$ \\
\hline$\gamma$ & $\begin{array}{l}\text { Parameter that governs strength of negative externality } \\
\text { Since } x_{i} \in(0,1) \text {, a larger } \gamma \text { implies stronger negative exter- } \\
\text { nalities, similar to Blanchard and Kiyotaki (1987) and } \\
\text { Harrison (2001) }\end{array}$ & $\gamma>0$ \\
\hline$\delta$ & $\begin{array}{l}\text { Parameter that governs strength of positive externality } \\
\text { Since } x_{i} \in(0,1) \text {, a larger absolute value of } \delta \text { implies stronger } \\
\text { positive externalities, similar to Blanchard and Kiyotaki } \\
\text { (1987) and Harrison (2001) }\end{array}$ & $\delta<0$ \\
\hline
\end{tabular}

Davis 2008). Rather than providing an exhaustive summary of unintended consequences, the model represents a first step at elucidating what we feel to be the most salient concepts at play in the above examples. In our model, unintended consequences may manifest themselves by making policy ineffective.

The economy comprises a large number of $N>1$ individuals, indexed by $i=1$, $\ldots, N$. These citizens are ex ante identical, before the policy is implemented: All citizens $i$ have the same preferences and receive the same net utility $u_{i}=\bar{u}$ from consumption of a good or service $x$ (say, time spent on research, as in Example 1 of the tenure clock, or a car as in Example 2 of Mexico City pollution). We standardize the range of $x$ to lie in the unit interval, that is, $x \in[0,1]$. Consumption of good $x$ at the original level $\bar{x}_{i}$ generates negative externalities, denoted $\bar{X}$. Similar to the literature on aggregate externalities, we write this original level of externality as $\bar{X} \equiv\left(\frac{1}{N} \sum_{i=1}^{N} \bar{x}_{i}\right)^{\gamma}$, for $\gamma>0$. The negative externality $\bar{X}$ is a number between 0 and 1 and reduces citizens' utility. In particular, the externality in this case affects utility multiplicatively, i.e., each citizen will experience a utility $\bar{u}_{i} \bar{X}$, which is less than $\bar{u}_{i}$. A negative externality reduces utility, but not below zero-if they experienced negative utility, citizens would be better off not consuming good $x$. We use a 
multiplicative form to indicate that each individual's utility is scaled by a factor proportional to the level of externalities in the economy. Intuitively, this specification captures the notion that individual citizens' utility is scaled up if there is a positive externality, and decreased if there is a negative externality.

In an effort to combat negative externalities, the policymaker institutes a policy requiring that each citizen reduce consumption from the original $\bar{x}_{i}$ to a lower level $x_{i}^{o}=x^{o}$, for all $i$, where the superscript 'o' denotes obedient. This requirement, if obeyed, will lower each citizen's utility to $u_{i}<\bar{u}$. Alternatively, some citizens (indexed by $j \neq i$ ) can disobey and find a way to circumvent the policy, thereby consuming $x_{j}^{c}>\bar{x}$ and obtaining a net utility of $u_{j}^{c}>\bar{u}$. The superscript 'c' denotes constructed utility.

When all citizens obey and reduce their consumption, this generates a positive externality $X$ (or a reduction in the existing negative externality) that is proportional to the reduction in consumption, i.e., $X=\left(\frac{1}{N} \sum_{i=1}^{N} \bar{x}_{i}-x_{i}^{o}\right)^{\delta}$. Here, $X$ is larger than one and denotes the positive externality or social benefit that arises when citizens obey the new policy mandate and restrict consumption. Each citizen takes $X$ as given, and $\delta<0$ reflects the degree of positive externalities now present in the economy. ${ }^{12}$ All citizens $i$ that obey receive the same utility $u_{i}=u$ after the policy, under the original preferences. As mentioned above, the externality affects utility multiplicatively, i.e., each obedient citizen $i$ will ultimately experience a utility $u_{i} X$.

Similarly, if some citizens $j \neq i$ disobey, they receive the same utility $u_{j}^{c}=u^{c}$ after the policy, under their new constructed choices. Both $u^{c}$ and $u$ are net of any costs the citizens may bear. We order citizens so that the first $N^{\prime}$ are the obeyers, and those indexed $j=N^{\prime}+1, \ldots, N$ are the disobeyers. As before, the $N^{\prime}$ obedient citizens generate a positive externality $X^{+}$, defined as $X^{+}=\left(\frac{1}{N^{\prime}} \sum_{i=1}^{N^{\prime}} \bar{x}-x_{i}^{o}\right)^{\delta}$. Here, $X^{+}$is again larger than one. ${ }^{13}$ By contrast, disobedient individuals increase consumption and own utility, but thereby impose a negative externality on the economy; i.e., when citizens disobey and increase consumption from $\bar{x}$ to $x_{j}^{c}>\bar{x}$, this generates a negative externality that is proportion to the average increase in consumption. This external effect is denoted $X^{-}=\left(\frac{1}{N-N^{\prime}} \sum_{j=N^{\prime}+1}^{N} x_{j}^{c}-\bar{x}\right)^{\gamma}$. This negative externality $X^{-}$is a number between 0 and 1 and therefore scales down all citizens' utility levels. Thus, the utility increase that disobeyers generate has a negative effect on society as a whole.

The aggregate effect on the economy depends on the balance between the positive externalities from those who obey, and negative externalities from those who disobey, which we write as a net externality effect: $X^{\text {net }}=X^{+}-X^{-}$. The net externality $X^{\text {net }}$ is lower than $X$ (the positive externality when everyone obeys) and

\footnotetext{
12 This framework is similar to that used in the macroeconomic literature on aggregate externalities, such as Blanchard and Kiyotaki (1987) and Harrison (2001).

${ }^{13}$ Since $x_{i}^{o}=x^{o}$ for all obeyers, in this formulation $X^{+}=X$. More generally, we could scale $X^{+}$down to reflect that the positive externality when only some obey, is weakly less than the externality when all obey, i.e., $X^{+} \leq X$.
} 
summarizes the overall impact of positive and negative externalities in the economy. ${ }^{14}$ Thus, when some citizens disobey, each obedient citizen $i$ receives utility $u_{i} X^{\text {net }}$, and each disobedient citizen $j$ experiences utility $u_{j}^{c} X^{\text {net }}$. For instance, in the case of Example 1 of the tenure clock from the Introduction, $X^{\text {net }}$ measures the overall impact on social welfare when we balance the following two effects: first, the increased social benefits from enhanced childcare among academics who abstain from research when on parental leave, and second, the decreased social benefits due to reduced childcare from those academics who abuse the system and use parental leave for research.

\section{Social Welfare Measures}

The policymaker constructs social welfare using an equal-weighted sum of individual utilities, as shown below. Hence, we write the following three expressions for social welfare. First, original social welfare before the policy was implemented is denoted $\bar{U}$. This quantity is defined as $\bar{U}=\sum_{i=1}^{N} \bar{u}_{i} \bar{X}$, where $\bar{X}$ is the original level of externality, as defined above. Since $\bar{u}_{i}=\bar{u}$, this implies that the original welfare can be written

$$
\bar{U}=N \bar{u} \bar{X} .
$$

Second, we write the social welfare $U$ if every citizen obeys the policy. That is, $U=\sum_{i=1}^{N} u_{i} X$. Since $u_{i}=u$, this implies that

$$
U=N u X .
$$

Finally, we express social welfare $U^{C}$ when some citizens $j$ disobey and construct new choices to deliver net utility $u_{j}^{c}$, in the following manner: $U^{C}=\sum_{j=N^{\prime}+1}^{N} u_{j}^{c} X^{\text {net }}+\sum_{i=1}^{N^{\prime}} u_{i} X^{\text {net }}$. This implies, because $u_{j}^{c}=u^{c}$ for all $j$, that social welfare under disobedience can be written

$$
U^{C}=\left(N-N^{\prime}\right) u^{c} X^{\mathrm{net}}+N^{\prime} u X^{\mathrm{net}} .
$$

We would like to understand the effectiveness of policy. Effectiveness may be conceptualized in several ways. The common thread is that a policy is effective if obeying the policy delivers higher per capita welfare to the citizens than disobeying, and is ineffective if it delivers lower per capita welfare. Two interesting measures of effectiveness can be found by answering the following questions: First is welfare $U$ that the government believes will occur (under the assumption that citizens will all obey the policy) higher than the actual welfare $U^{C}$ under disobedience? Second is the welfare $\bar{U}$ in the original, pre-policy economy higher than actual welfare $U^{C}$ when some citizens disobey? We evaluate the first measure of policy effectiveness with the difference $U-U^{C}$. Similarly, we assess the second measure of effectiveness, with the difference $\bar{U}-U^{C}$. We will focus on the first measure, which we write

${ }^{14}$ The result that $X^{\text {net }}<X$ follows from the fact that $X^{+}=X>1$ and $X^{-}<1$. 
as $E^{1}$, where $E$ denotes 'effectiveness.' Using equations (3) and (4), we first write $U-U^{C}$ in the following

$$
U-U^{C}=N u X-\left[\left(N-N^{\prime}\right) u^{c} X^{\mathrm{net}}+N^{\prime} u X^{\mathrm{net}}\right] .
$$

Now we rewrite the above expression in per capita terms, dividing $U-U^{C}$ by the total population $N$, to obtain our policy effectiveness measure $E^{1}$ :

$$
\begin{aligned}
E^{1} & =\frac{U-U^{C}}{N}=u X-\frac{N-N^{\prime}}{N} u^{c} X^{\mathrm{net}}-\frac{N^{\prime}}{N} u X^{\mathrm{net}} \\
& =u X-p u^{c} X^{\mathrm{net}}-(1-p) u X^{\mathrm{net}} \\
& =u X-p u^{c} X^{\mathrm{net}}-u X^{\mathrm{net}}+p u X^{\mathrm{net}} \\
& =\left[u X-u X^{\mathrm{net}}\right]-p\left[u^{c} X^{\mathrm{net}}-u X^{\mathrm{net}}\right],
\end{aligned}
$$

where the second line uses the relation $p=\frac{N-N^{\prime}}{N}$ and $(1-p)=\frac{N^{\prime}}{N}$. The quantity $p$ represents the empirical probability that citizens disobey the novel policy rule. Policy is effective if $E^{1}>0$, and policy is ineffective if $E^{1} \leq 0$.

The expression in Eq. (5) is intuitive: It says that whether a policy is effective depends on the trade-off between the two terms in square brackets. The first term, $u X-u X^{\text {net }}$, compares the average utility level if everyone obeyed, and the average utility level of obeyers, if only some citizens obeyed. The first term is always positive, since $X>X^{\text {net }}$. The second term is the (probability-weighted) difference between utility of disobedient and obedient citizens. This latter term is also positive, since $u^{c}>u$. In general, the quantity $E^{1}$, as a difference between two positive terms, can be positive or negative, i.e., policy may be effective or ineffective. Next, we explore the impact of the disobedient proportion $p$ on policy effectiveness.

\section{Policy Effectiveness in the Model}

How does the effectiveness of policy depend on $p$ ? We can address this question by taking derivatives. First, we differentiate the expression in Eq. (5), to glean a sense of whether larger $p$ connotes more or less effective policy:

$$
\frac{\mathrm{d} E^{1}(\cdot)}{\mathrm{d} p}=-\left[u^{c} x^{\mathrm{net}}-u X^{\mathrm{net}}\right]
$$

The expression in Eq. (6) is negative, since $u^{c}>u$.

Result 1 Policy effectiveness decreases with the proportion $p$ of disobedient citizens.

Second, we would like to answer policy-related questions such as, What is the threshold probability $\bar{p}$ such that policy is minimally effective, i.e., such that $E^{1}(\bar{p})=0$ ? And is this $\bar{p}$ reasonable? From Eq. (5), this occurs if the following condition holds: $p\left[u^{c} X^{\text {net }}-u X^{\text {net }}\right]=u X-u X^{\text {net }}$, or, equivalently, 


$$
\bar{p}=\frac{u X-u X^{\mathrm{net}}}{u^{c} X^{\mathrm{net}}-u X^{\mathrm{net}}} .
$$

The value of $p$ in Eq. (7) is useful, as it tells us the threshold level where policy just starts to become ineffective.

Is $\bar{p}$ A Valid Probability? For $\bar{p}$ to be a valid probability, i.e., $p \in[0,1]$, we require that Eq. (7) be positive. This condition holds, upon inspection, because both the numerator and denominator are positive. We also require that $\bar{p}$ be less than 1 , i.e., $\frac{u X-u X^{\text {net }}}{u^{c} X^{\text {net }}-u X^{\text {net }}} \leq 1$, or $u X-u X^{\text {net }} \leq u^{c} X^{\text {net }}-u X^{\text {net }}$, which in turn holds if $u^{c} \geq \frac{u X}{X^{\text {net }}}$. Intuitively, this condition requires that the payoff to disobeying be large enough relative to the payoff from obeying. In general, these conditions hinge on empirical data, which suggests that future work on unintended consequences could meaningfully explore an experimental approach.

Result $2 \bar{p}$ is a valid probability if $u^{c} \geq \frac{u X}{X^{\text {net'}}}$, i.e., if citizens' payoff to disobeying is large enough.

We summarize our preceding discussion and results in the following proposition.

Proposition (Existence of Policy Ineffectiveness and Unintended Consequences under Ambiguity Neglect) Consider an economy with a large number of $N>1$ citizens, where a novel policy (e.g., to restrict consumption) is implemented. Further, suppose that citizens with original utility $u_{i}=\bar{u}, i=1, \ldots N$, can choose to obey the policy and obtain net utility $u<\bar{u}$. Denote the probability of citizen disobedience by $p \in[0,1]$. If $u^{c}$ is sufficiently greater than $u$, then there exists a threshold probability $\bar{p}$ such that, for $p>\bar{p}$, the policy is ineffective.

Example $A$ (Existence of threshold probability) Suppose $u^{c}=10 ; u=2 ; X=2$ and $X^{\text {net }}=\frac{1}{2}$. Then according to Eq. (7), $\bar{p}$ must satisfy

$$
\bar{p}=\frac{u X-u X^{\mathrm{net}}}{u^{c} X^{\mathrm{net}}-u X^{\mathrm{net}}}=\frac{(2 \cdot 2)-\left(2 \cdot \frac{1}{2}\right)}{\left(10 \cdot \frac{1}{2}\right)-\left(2 \cdot \frac{1}{2}\right)}=\frac{4-1}{5-1}=\frac{3}{4} .
$$

In the context of Example A, the model-implied threshold proportion is a reasonable probability, and policy is ineffective after the fraction of disobeyers exceeds $3 / 4$.

Example B (Irrelevant threshold probability). This example features the same setup as above, except that $u^{c}=6$. Then, using the same logic as above, according to Eq. (7), $\bar{p}$ must satisfy

$$
\bar{p}=\frac{u X-u X^{\mathrm{net}}}{u^{c} X^{\mathrm{net}}-u X^{\mathrm{net}}}=\frac{(2 \cdot 2)-\left(2 \cdot \frac{1}{2}\right)}{\left(6 \cdot \frac{1}{2}\right)-\left(2 \cdot \frac{1}{2}\right)}=\frac{4-1}{3-1}=\frac{3}{2} .
$$


In this latter case, even if the entire population disobeyed, it would not be enough for policy to be ineffective. That is, policy is always effective. Intuitively, the increased utility occasioned by disobedience $\left(u^{c}=6\right)$ was not large enough relative to obedience $(u=2)$ for it to be worthwhile. In light of the above examples, it appears valuable to explore settings where one can assess empirically, what sort of levels of $p$ might be observed with real-world subjects.

\section{Conclusion}

In this paper, we provide a simple framework and formalization of unintended consequences. We employ concepts often used by many economists, but our point is more general-it applies across the social sciences. The idea is that there is a threshold probability of disobedience, denoted $\bar{p}$, of which the policymaker may be unaware, such that for $p>\bar{p}$, policy is ineffective if implemented. Under such circumstances, it pays citizens more to disobey than to obey. These results are summarized in our proposition, in "Our Model of Unintended Consequences" section.

Ultimately, we are interested in learning about how policymakers can improve their practices, so as to avoid negative unintended consequences, when possible. ${ }^{15}$ Policymakers may, for example, utilize questionnaires that assess citizens' expected choices in some manner, before implementing policies. In addition, the findings in our present paper may lend themselves well, in future work, to being evaluated in empirical and experimental settings. In particular, our framework lends itself well to using experiments as a method of testbedding policies (see, for example, Plott 1994; Plott and Smith 2008), before they are actually implemented.

Acknowledgements We are grateful for comments from seminar participants at the Welch College of Business and Technology, and from Pietro Battiston and Meg Meyer.

\section{References}

Akerlof, G. 1970. The Market for Lemons: Quality Uncertainty and the Market Mechanism. Quarterly Journal of Economics 84(3): 485-500.

Andvig, J., and K. Moene. 1990. How Corruption May Corrupt. Journal of Economic Behavior and Organization 13(1): 63-76.

Antecol, H., K. Bedard, and J. Stearns. 2018. Equal but Inequitable: Who Benefits from Gender-Neutral Tenure Clock Stopping Policies? American Economic Review 108(9): 2420-2441.

Arrow, K., and G. Debreu. 1954. Existence of an Equilibrium for a Competitive Economy. Econometrica 22(3): 265-290.

Bazerman, M., and D. Watkins. 2004. Predictable Surprises. Harvard Business School Press.

Benartzi, S., and R. Thaler. 1995. Myopic Loss Aversion and the Equity Premium Puzzle. Quarterly Journal of Economics 110(1): 73-92.

Benhabib, J., and R. Farmer. 1999. Indeterminacy and Sunspots in Macroeconomics. Handbook of Macroeconomics 1A: 387-448.

15 For an alternative, agent-based approach to unintended consequences, see Tesfatsion (2011). 
Blanchard, O., and N. Kiyotaki. 1987. Monopolistic Competition and the Effects of Aggregate Demand. American Economic Review 77(4): 647-666.

Bocchiaro, P., and P. Zimbardo. 2017. On the Dynamics of Disobedience: Experimental Investigations of Defying Unjust Authority. Psychology Research and Behavior Management 10: 219-229.

Bocchiaro, P., P. Zimbardo, and P. Van Lange. 2012. To Defy or Not to Defy: An Experimental Study of the Dynamics of Disobedience and Whistle-Blowing. Social Influence 7(1): 35-50.

Braess, D. 1969. Uber Ein Paradoxon aus Der Verkehrsplanung. Unternehmensforschung 12: 258-268.

Brunnermeier, M., P. Bolton, and L. Veldkamp. 2013. Leadership, Coordination and Mission-driven Management. Review of Economic Studies 80(2): 512-537.

Campbell, D. 1979. Assessing the Impact of Planned Social Change. Evaluation and Program Planning 2(1): 67-90.

Cartwright, E., and A. Stepanova. 2017. Efficiency in a Forced Contribution Threshold Public Good Game. International Journal of Game Theory 46(4): 1163-1191.

Cherry, T., S. Kallbekken, S. Kroll, and D. McEvoy. 2013. Cooperation In and Out of Markets: An Experimental Comparison of Public Good Games and Markets with Externalities. Economics Letters 120(1): 93-96.

Davide, M., and S. Passini. 2010. The Obedience-Disobedience Dynamic and the Role of Responsibility. Journal of Community and Applied Social Psychology 20(1): 1-14.

Davis, L. 2008. The Effect of Driving Restrictions on Air Quality in Mexico City. Journal of Political Economy 116(1): 38-81.

Dennett, D. 2007. Breaking the Spell: Religion as a Natural Phenomenon. New York: Penguin Books.

Dequech, D. 2000. Fundamental Uncertainty and Ambiguity. Eastern Economic Journal 26(1): 41-60.

Doleac, J., and A. Mukherjee. 2019. The Moral Hazard of Lifesaving Innovations: Naloxone Access, Opioid Use, and Crime. Tech. rep., Working Paper.

Ederer, F., R. Holden, and M. Meyer. 2018. Gaming and Strategic Opacity in Incentive Provision. Rand Journal of Economics 49(4): 819-854.

Elster, J. 2007. Explaining Social Behavior: More Nuts and Bolts for the Social Sciences. New York: Cambridge University Press.

Epstein, L., M. Marinacci, and K. Seo. 2007. Coarse Contingencies and Ambiguity. Theoretical Economics 2(4): 355-394.

Fudenberg, D., and J. Tirole. 1991. Game Theory. Cambridge, MA: MIT Press.

Ghirardato, P. 2001. Coping with Ignorance: Unforeseen Contingencies and Non-additive Uncertainty. Economic Theory 17(2): 247-276.

Gilboa, I., and D. Schmeidler. 1989. Maxmin Expected Utility with Non-unique Prior. Journal of Mathematical Economics 18(2): 141-153.

Goodhart, C. 1975. Problems of Monetary Management: The U.K. experience. Papers in Monetary Economics. I. Reserve Bank of Australia I.

Harari, Y. 2015. Sapiens: A Brief History of Humankind. New York: Harper Collins Publishers.

Hardin, G. 1968. The Tragedy of the Commons. Science 162(3859): 1243-1248.

Harrison, S. 2001. Indeterminacy in a Model with Sector-specific Externalities. Journal of Economic Dynamics and Control 25(5): 747-764.

Hertwig, R., G. Barron, E. Weber, and I. Erev. 2005. Decisions from Experience and the Effect of Rare Events in Risky Choice. Psychological Science 15(8): 534-539.

Kahneman, D. 2011. Thinking Fast and Slow. London: Penguin Books.

Kahneman, D., I. Ritov, and D. Schkade. 1999. Economic Preferences or Attitude Expressions? An Analysis of Dollar Responses to Public Issues. Journal of Risk and Uncertainty 19(1-3): 203-235.

Karni, E., and M. Vierø. 2013. Reverse Bayesianism: A Choice-Based Theory of Growing Awareness. American Economic Review 103(7): 2790-2810.

Karni, E., and M. Vierø. 2017. Awareness of Unawareness: A Theory of Decision Making in the Face of Ignorance. Journal of Economic Theory 168: 301-328.

Keynes, J. 1936. The General Theory of Employment. Interest and Money: Harcourt, Brace, and Company, New York.

Kochov, A. 2018. A Behavioral Definition of Unforeseen Contingencies. Journal of Economic Theory 175: 265-290.

Kydland, F., and E. Prescott. 1977. Rules Rather than Discretion: The Inconsistency of Optimal Plans. Journal of Political Economy 85(3): 473-491.

Ledyard, J., 1995. Public Good: A Survey of Experimental Results. In Handbook of Experimental Economics, ed. J. Kagel, A. Roth, 111-194. Princeton, NJ: Princeton University Press. 
Lerner, J., and D. Keltner. 2001. Fear, Anger and Risk. Journal of Personality and Social Psychology 81(1): 146-159.

Levy, G., and R. Razin. 2015. Correlation Neglect, Voting Behavior and Information Aggregation. American Economic Review 105(4): 1634-1635.

Lichtenstein, S., and P. Slovic. 2006. The Construction of Preference. New York: Cambridge University Press.

Lucas, R. 1976. Econometric Policy Evaluation: A Critique. Carnegie-Rochester Conference Series on Public Policy 1: 19-46.

Mandeville, B. 1714. The Fable of the Bees, or Private Vices, Publick Benefits. Printed for J. Roberts, London.

Marx, K. 1867. Das Kapital. Kritik Der Politischen Oekonomie. Hamburg: Verlag von Otto Meisner.

Mas-Colell, A., M. Whinston, and J. Green. 1995. Microeconomic Theory. Oxford Press.

McCracken, G. 1988. Culture and Consumption: New Approaches to the Symbolic Character of Consumer Goods and Activities. Bloomington, IN: Indiana University Press.

Merton, R.K. 1936. The Unanticipated Consequences of Purposive Social Action. American Sociological Review 1(6): 894-904.

Minardi, S., and A. Savochkin. 2019. Subjective Contingencies and Limited Bayesian Updating. Journal of Economic Theory 183: 1-45.

Nash, J. 1950. The Bargaining Problem. Econometrica 18: 155-162.

Ortoleva, P., and E. Snowberg. 2015. Overconfidence in Political Behavior. American Economic Review 105(2): 504-535.

Payne, J., J. Bettman, and D. Schkade. 1999. Measuring Constructed Preferences: Towards a Building Code. Journal of Risk and Uncertainty 19(1-3): 243-270.

Plott, C. 1994. Market Architectures, Institutional Landscapes and Testbed Experiments. Economic Theory 4(1): 3-10.

Plott, C., and V. Smith. 2008. Mechanism Design and Policy Applications. In Handbook of Experimental Economics Results, ed. C. Plott and V. Smith, 619-623. New York: North Holland.

Poovey, M. 1998. A History of the Modern Fact: Problems of Knowledge in the Sciences of Wealth and Society. Chicago: University of Chicago Press.

Rashes, M. 2001. Massively Confused Investors Making Conspicuously Ignorant Choices: MCI-MCIC. Journal of Finance LVI 56(5): 1911-1927.

Rothschild, M., and J. Stiglitz. 1976. Equilibrium in Competitive Insurance Markets: An Essay on the Economics of Imperfect Information. Quarterly Journal of Economics 90(4): 629-649.

Schmeidler, D. 1989. Subjective Probability and Expected Utility Without Additivity. Econometrica 57(3): 571-587.

Shiller, R.J. 2017. Narrative Economics. American Economic Review 107(4): 967-1004.

Siebert, H. 2003. Der Kobra-Effekt. Wie Man Irrwege Der Wirtschaftspolitik Vermeidet. Munich: Piper Verlag.

Simon, D., D. Krawczyk, A. Bleicher, and K. Holyoak. 2008. The Transience of Constructed Preferences. Journal of Behavioral Decision Making 21(1): 1-14.

Sims, C. 2003. Implications of Rational Inattention. Journal of Monetary Economics 50(3): 665-690.

Smith, A. 1776. An Inquiry into the Nature and Causes of the Wealth of Nations. London: William Strahan.

Spence, M. 1973. Job Market Signalling. Quarterly Journal of Economics 87: 355-374.

Tesfatsion, L. 2011. Agent-Based Modeling and Institutional Design. Eastern Economic Journal 37(1): 13-19.

Publisher's Note Springer Nature remains neutral with regard to jurisdictional claims in published maps and institutional affiliations. 